(CC BY 4.0) | ISSN 2525-3409 | DOI: http://dx.doi.org/10.33448/rsd-v9i8.2594

Efeito do uso de probióticos, prebióticos e simbióticos na Doença Hepática Gordurosa

\title{
Não Alcoólica
}

Effect of the use of probiotics, prebiotics and symbiotics in Non-Alcoholic Fatty Liver

Disease

Efecto del uso de probióticos, prebióticos y simbioticos en Enfermedad del Hígado

\section{Graso No Alcohólico}

Recebido: 19/01/2020 | Revisado: 28/01/2020 | Aceito: 22/06/2020 | Publicado: 04/07/2020

Mickael de Paiva Sousa

ORCID: https://orcid.org/0000-0002-8446-1351

Universidade Federal do Piauí, Brasil

E-mail: mickaelpaivasousa@gmail.com

Joyce Sousa Aquino Brito

ORCID: https://orcid.org/0000-0002-8829-2575

Universidade Federal do Piauí, Brasil

E-mail: joycesousa.ab@ hotmail.com

Pedro Lucas Alves Ferreira

ORCID: https://orcid.org/0000-0002-1975-5054

Universidade Federal do Piauí, Brasil

E-mail: p.lucasnutricionista@gmail.com

Suhelen Maria Brasil da Cunha Gama

ORCID: https://orcid.org/0000-0002-5273-5426

Universidade Federal do Piauí, Brasil

E-mail: suhelen_gama@hotmail.com

Betânia de Jesus e Silva de Almendra Freitas

ORCID: https://orcid.org/0000-0002-7797-735X

Universidade Federal do Piauí, Brasil

E-mail: bsaf@ufpi.edu.br

\section{Resumo}

Introdução: A Doença Hepática Gordurosa Não Alcoólica (DHGNA) é um espectro de doenças hepáticas crônicas, sendo a mais comum devido à prevalência de obesidade em todo o mundo. Nesse contexto, há estudos existentes na literatura que ratificam os potenciais 
efeitos de microrganismos frente às complicações da DHGNA. Objetivo: A presente revisão se propõe a verificar as evidências sobre o efeito de probióticos, prebióticos e simbióticos na (DHGNA). Metodologia: Realizou-se uma busca de artigos publicados nas bases de dados Science Direct, PubMed e Cochrane, utilizando-se a combinação de descritores cadastrados nos Descritores em Ciências da Saúde (DeCS): non- alcoholic fatty liver disease; microbiome; nutritional intervention; clinical trial. Quinze artigos originais entre os anos de 2012 e 2018 foram elegidos. Resultados: Estudos que utilizaram probióticos, prebióticos e simbiótico na DHGNA observaram melhora em alguns parâmetros que contribuem para progressão da doença, como: ação de enzimas pró-oxidantes, redução da adiposidade, inflamação e fibrose no fígado, regulação da flora bacteriana intestinal, entre outros. Se tratando de bactérias probióticas, estudos relatam que as mesmas previnem o dano hepático, melhora o acúmulo de gordura visceral e a sensibilidade à insulina. Entre os efeitos dos prebióticos, destacam-se a atenuação da extensão da DHGNA, restaurando a homeostase da microbiota intestinal e a função da barreira epitelial intestinal. Os simbióticos, por sua vez, diminuíram significativamente os níveis de alanina aminotransferase, um marcador de lesão no fígado, e os níveis séricos de TNF- $\alpha$ e PCR. Conclusão: Terapias direcionadas à microbiota intestinal têm se tornado importantes ferramentas para o tratamento da DHGNA, uma vez que existem na literatura, relatos experimentais que destacam uma série de benefícios por meio do uso de probióticos, prebióticos e simbióticos. No entanto, são necessários mais estudos acerca do presente tema.

Palavras-chave: Doença hepática gordurosa não alcoólica; Microbiota; Ensaio clínico.

\section{Abstract}

Introduction: Non-Alcoholic Fatty Liver Disease (NAFLD) is a spectrum of chronic liver diseases, being the more common due to obesity prevalence around the world. In this context, there are studies in the literature that ratify the potential effects of microorganisms against the complications of NAFLD. Objective: This review is designed as a check on probiotics, prebiotics and symbiotics in non-alcoholic fatty liver disease. Methodology: a search of articles published in the database Science Direct, PubMed and Cochrane, using a combination of descriptors registered in the Descriptors in Health Sciences (DeCS): non-alcoholic fatty liver disease; microbiome; nutritional intervention; clinical trial. Fifteen original articles were chosen between the years of 2012 and 2018. Results: Studies that used probiotics, prebiotics and symbiotics in NAFLD showed improvement in some parameters that contribute to disease progression, such as: pro-oxidant enzyme action, reduction of adiposity, inflammation and 
fibrosis in the liver, regulation of intestinal bacterial flora, among others. If they are probiotic bacteria, studies report that they prevent liver damage, improve visceral fat accumulation and insulin sensitivity. Among the effects of prebiotics, the attenuation of the extension of NAFLD, restoring the intestinal microbiota homeostasis and the function of the intestinal epithelial barrier are outstanding. Symbiotics, in turn, significantly decreased levels of alanine aminotransferase, a marker of liver damage, and serum levels of TNF $\alpha$ and PCR. Final considerations: Therapies directed to the intestinal microbiota have become important tools for the treatment of NAFLD, since there are in the literature experimental reports that highlight a series of benefits through the use of probiotics, prebiotics and symbiotics. However, further studies are needed on this topic.

Keywords: Non-alcoholic fatty liver disease; Microbiome; Clinical trial.

\section{Resumen}

Introducción: La Enfermedad del Hígado Graso No Alcohólico (EHGNA) es un espectro de enfermedad hepática crónica, siendo la más común debido a la prevalencia de obesidad en todo el mundo. En este contexto, existen estudios en la literatura que confirman los posibles efectos de los microorganismos sobre las complicaciones de la EHGNA. Objetivo: Esta revisión tiene como objetivo verificar la evidencia sobre el efecto de los probióticos, prebióticos y simbióticos en la enfermedad del hígado graso no alcohólico. Metodología: Se realizó una búsqueda de artículos publicados en las bases de datos Science Direct, PubMed y Cochrane utilizando la combinación de descriptores registrados en los Descriptores en Ciencias de la Salud (DeCS): enfermedad del hígado graso no alcohólico; microbioma intervención nutricional; ensayo clínico Se eligieron quince artículos originales entre 2012 y 2018. Resultados: Los estudios que utilizan probióticos, prebióticos y simbióticos en EHGNA mostraron una mejora en algunos parámetros que contribuyen a la progresión de la enfermedad, como la acción de las enzimas prooxidantes, la reducción de la adiposidad, la inflamación y la fibrosis en el hígado, la regulación de la flora bacteriana intestinal, entre otros. otros En el caso de las bacterias probióticas, los estudios informan que previenen el daño hepático, mejoran la acumulación de grasa visceral y la sensibilidad a la insulina. Los efectos prebióticos incluyen la atenuación de la extensión de EHGNA, la restauración de la homeostasis de la microbiota intestinal y la función de barrera epitelial intestinal. Los simbióticos, a su vez, disminuyeron significativamente los niveles de alanina aminotransferasa, un marcador de daño hepático y los niveles séricos de TNF- $\alpha$ y PCR.

Conclusión: Las terapias dirigidas a la microbiota intestinal se han convertido en 
herramientas importantes para el tratamiento de la EHGNA, ya que existen en la literatura informes experimentales que destacan una serie de beneficios a través del uso de probióticos, prebióticos y simbióticos. Sin embargo, se necesitan más estudios sobre este tema.

Palabras clave: Enfermedad del hígado graso no alcohólico; Microbiota; Ensayo clínico.

\section{Introdução}

O trato gastrointestinal dos mamíferos é o principal local para bactérias comensais, existindo assim, mais de 1014 microrganismos no corpo humano, que desempenham papéis importantes na manutenção da saúde humana. A abundância e a composição da microbiota intestinal são altamente variáveis no contexto de diferentes condições que contribuem para o desenvolvimento de várias doenças e, nos últimos anos, um grande número de estudos revelou os papéis críticos da microbiota intestinal no desenvolvimento de doenças metabólicas, incluindo diabetes mellitus tipo 1 e 2, obesidade, doença cardiovascular e doenças crônicas do fígado (Minemura \& Shimizu, 2015; Ma, Zhou \& Li, 2017).

A oença Hepática Gordurosa Não Alcoólica (DHGNA) é um espectro de doenças hepáticas crônicas, incluindo esteatose simples, Esteato-hepatite Não Alcoólica (NASH), fibrose, cirrose e Carcinoma Hepatocelular (HCC). A DHGNA é a doença hepática crônica mais comum devido à prevalência de obesidade em todo o mundo. Entre outros fatores, a alteração da microbiota intestinal também promove o desenvolvimento da DHGNA por processos mediadores de inflamação, resistência à insulina, ácidos biliares e metabolismo da colina. Como resultado, a elucidação sobre os papeis da microbiota intestinal na DHGNA ressalta a importância das terapias direcionadas à mesma. Existem várias maneiras de manipular a microbiota intestinal, por exemplo, através do uso de probióticos, prebióticos, simbióticos, antibióticos e alguns componentes ativos de ervas medicinais (Wree, Broderick, Canbay, Hoffman \& Feldstein, 2013; Mouzaki \& Bandsma, 2015; Shen, Obin \& Zhao, 2013).

Probióticos são microrganismos vivos que, quando administrados em quantidade adequada, afetam beneficamente o hospedeiro, enquanto os prebióticos são componentes alimentares não digeríveis que afetam beneficamente o hospedeiro, estimulando seletivamente a proliferação ou atividade de populações de bactérias desejáveis. Os simbióticos, por sua vez, consistem na associação de probióticos e prebióticos, que quando selecionados e consumidos apropriadamente podem aumentar os efeitos benéficos de cada um deles, uma vez que o estímulo de cepas probióticas conhecidas leva à escolha dos pares simbióticos substratomicrorganismo ideais (Oliveira \& Arestrup, 2012). 
Trabalhos existentes na literatura ratificam os potenciais efeitos desses microrganismos frente às complicações da DHGNA, seja por estimular a função imune, por meio do favorecimento da atividade de enzimas antioxidantes, seja por reduzir o acúmulo de gordura e inflamação no tecido hepático, ou por ainda melhorar a flora intestinal (Matsumoto et al., 2017; Ren, Huang \& Cheng, 2014; Modifi, 2017).

Diante de tais aspectos, a presente revisão se propõe a verificar as evidências sobre a eficácia de probióticos, prebióticos e simbióticos na DHGNA.

\section{Metodologia}

O estudo caracteriza-se como uma revisão da literatura, aprofundando-se sobre a eficácia de probióticos, prebióticos e simbióticos na doença hepática gordurosa não alcoólica e, tem como propósito estabelecer um debate entre ideias de diferentes autores. É uma síntese crítica dos conhecimentos disponíveis mediante a análise e interpretação de dados bibliográficos pertinentes.

Foram utilizados artigos nos idiomas inglês e português. A busca na literatura foi realizada nas bases de dados Science Direct, PubMed e Cochrane. Utilizou-se a combinação de descritores controlados, aqueles estruturados e organizados para facilitar o acesso à informação, cadastrados nos Descritores em Ciências da Saúde (DeCS): non-alcoholic fatty liver disease; microbiome; nutritional intervention; clinical trial. 
Figura 1. Fluxograma da seleção dos estudos.

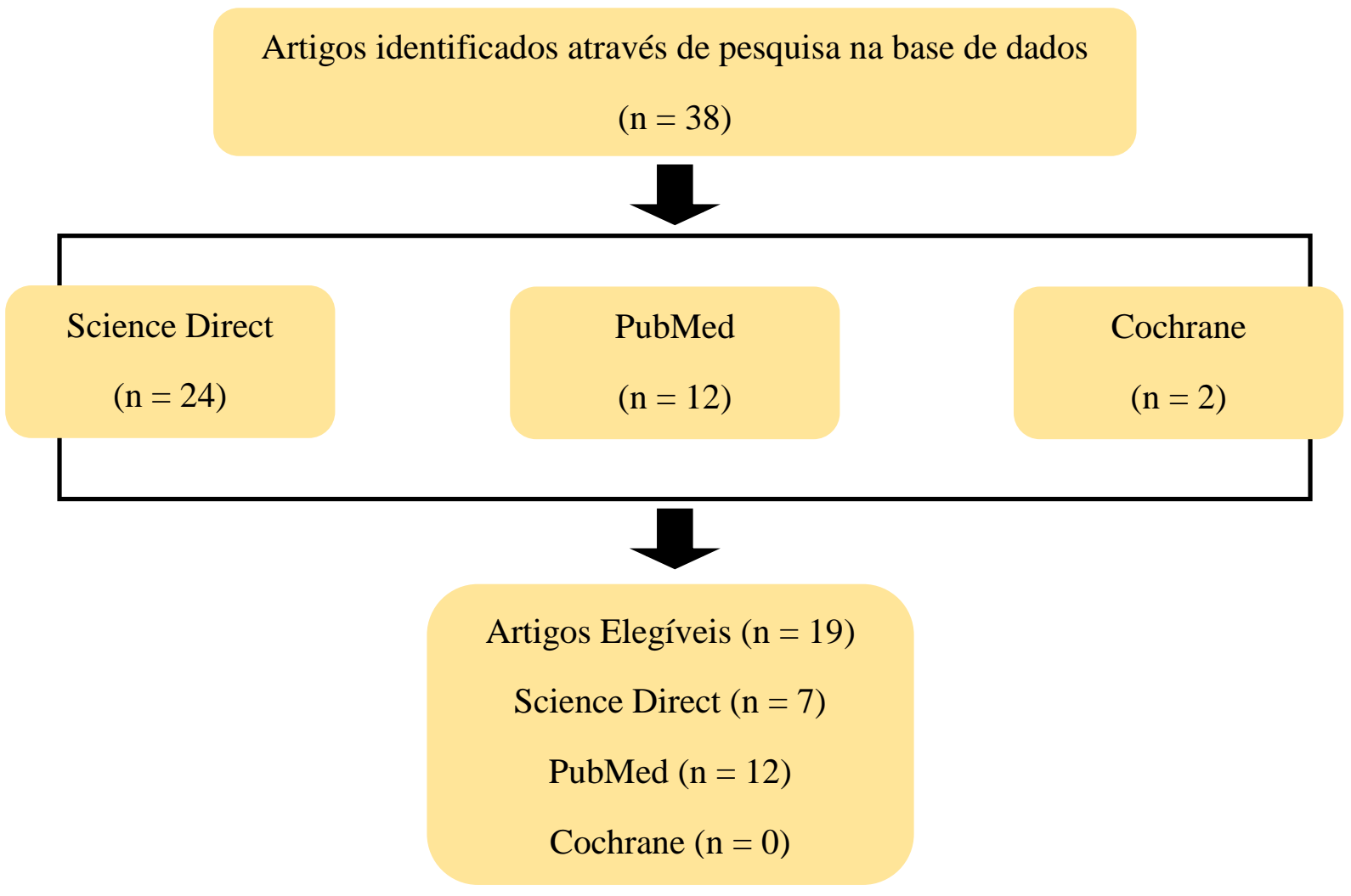

Fonte: Autores

O levantamento bibliográfico abrangeu os seguintes tipos de estudos: transversal, caso-controle e ensaio clínico randomizado. Os critérios de elegibilidade para inclusão no estudo foram: texto completo disponível online; artigos científicos que contemplassem a temática; artigos publicados no período de 2012 a 2019, divulgados em língua portuguesa ou inglesa. Após a busca, foi realizada a pré-seleção dos artigos por meio da leitura criteriosa dos títulos e resumos, no intuito de verificar a adequação dos mesmos aos critérios estabelecidos. Foram excluídos artigos fora da margem de tempo estipulada.

\section{Doença Hepática Gordurosa Não Alcoólica}

A DHGNA é a causa mais comum de doença crônica hepática em todo o mundo e tem sido reconhecida como manifestação precoce de obesidade e síndrome metabólica. Caracterizada pelo acúmulo de lipídeos no fígado, pode levar a estágios mais avançados com fibrose, cirrose e hepatocarcinoma. Nessa fase, a doença representa a forma inflamatória 
classificando-se como Esteato-hepatite Não Alcoólica (EHNA) (Pacifico, Nobili, Anania, Verdecchia \& Chiesa, 2011).

Segundo Camargo (2014), a distribuição da DHGNA está intimamente relacionada ao diabetes e a obesidade, doenças que atingiram proporções epidêmicas mundiais. A prevalência mundial dessa doença na população obesa está entre 40 e 90\%, nos países ocidentais, 14 a 27\% da população tem DHGNA, cinco a 10\% destes, desenvolverão EHNA, dez a $20 \%$ terão fibrose avançada, aproximadamente cinco por cento terão cirrose, dois por cento ao ano terão carcinoma hepatocelular.

A DHGNA é clinicamente silenciosa, sendo geralmente detectada pelo nível anormal de enzimas hepáticas na avaliação clínica de rotina. Os sintomas, quando presentes, são dificilmente relacionados com a gravidade da condição e podem levar a outras afecções. Os achados clínicos mais comuns são fadiga, dor no quadrante superior direito, hepatomegalia, obesidade, acanthosis nigricans, entre outros (Salgado Júnior, Santos, Sankarankutty \& Castro e Silva 2006).

A DHGNA é resultante de alterações patológicas crônicas, que envolvem o aumento da síntese hepática, oxidação deficiente e redução da secreção hepática de lipídeos, obesidade, doença hepática alcoólica, caquexia, distúrbios metabólicos, hepatite $\mathrm{C}$, resistência à insulina e diabetes. Apresenta-se em duas formas simples, em pacientes não alcoólicos, sem inflamação ou fibrose devido ao estresse oxidativo, gerando espécies reativas de oxigênio e peroxidação lipídica (Contrim, 2009).

A resistência à insulina tem sido reconhecida como fundamental no desenvolvimento da esteatose. A hiperinsulinemia presente é resultante da predisposição genética, do excesso de oferta de ácidos graxos livres ou da exposição a níveis elevados de Fator de Necrose Tumoral-alfa (TNF- $\alpha$ ), Interleucina 6 (IL-6) ou outros mediadores peptídicos (Harryson \& Day, 2007).

Tanto a resistência à insulina como as comorbidades que compõem a síndrome metabólica são consideradas causas primárias da DHGNA. Outros fatores, como mutações (apo B), deficiências (colina), excesso de oferta de carboidratos (nutrição parenteral total), drogas (como tamoxifeno, metotrexato), vírus (como da hepatite $\mathrm{C}$, da imunodeficiência humana) e toxinas (como hidrocarbonetos), são considerados como causas secundárias (Portela, Melo \& Sampaio, 2013).

O tratamento tem como objetivo inicial a resolução das anormalidades histológicas que foram identificadas por meio da biopsia hepática. O tratamento das condições associadas, 
como DM2, obesidade e dislipidemias também é essencial. Não existe tratamento específico para a doença, sendo este mais dirigido a cada anormalidade presente (Younossi, 2008).

Mudanças no estilo de vida são fundamentais no tratamento de DHGNA e incluem o aconselhamento dietoterápico e exercícios regulares. A base fisiopatológica para essa recomendação é a redução de peso, que promove a diminuição das células brancas do tecido adiposo e diminui a resistência à insulina. $\mathrm{O}$ exercício pode ainda aumentar a sensibilidade das células musculares à insulina. Estudos têm demonstrado que a redução de peso e o exercício causam diminuição nos níveis de dano hepático e devem ser o foco principal da conduta clínica. A redução de dez por cento do peso corporal pode representar melhora nos parâmetros bioquímicos, incluindo melhora no perfil lipídico e resistência à insulina, assim como nos níveis de aminotransferases, porém mais estudos são necessários para determinar se a redução de peso, a longo prazo, ocasiona melhora na histologia do tecido hepático, principalmente na presença de fibrose hepática (Portela, Melo \& Sampaio, 2013).

\section{Microbiota intestinal e Doença Hepática Gordurosa Não Alcoólica}

A microbiota intestinal desempenha um papel crítico no desenvolvimento de doenças metabólicas, produzindo metabólitos microbianos como Ácidos Graxos de Cadeia Curta (AGCC) que regulam o fornecimento de energia ao hospedeiro ou modulando as vias de sinalização do metabolismo energético no hospedeiro (Cani et al., 2009).

Em seu estudo, Bäckhed et al. (2012) revelou que a microbiota intestinal promove a absorção de monossacarídeos, acelerando a lipogênese hepática de novo e suprimindo o fator adipócitário induzido pelo jejum, resultando em acúmulo de triglicérides nos adipócitos. $\mathrm{O}$ estudo de Moschen, Kaser e Tilg. (2013) também evidenciou a ação da microbiota intestinal afetando o metabolismo energético do hospedeiro.

Os pacientes com DHGNA são tipicamente caracterizados por um supercrescimento bacteriano no intestino delgado, que pode prejudicar a junção intestinal e subsequentemente aumentar a permeabilidade à agentes infecciosos. Essa situação também induz a expressão hepática do Receptor do Tipo Toll 4 (TLR4) e a liberação de Interleucina-8 (IL-8) que estimula a reação inflamatória. A disbiose intestinal instalada provoca um aumento dos níveis de lipopolissacarídeos na circulação, que por sua vez, irá acarretar reação inflamatória e resistência a insulina. Tais fatores irão acelerar o acúmulo de gordura e inflamação nos hepatócitos, formando um ciclo vicioso que só contribui para a rápida evolução da DHGNA (Caesar, Fåk \& Bäckhed., 2012). 
Outro aspecto determinante para o desenvolvimento da DHGNA, e que se relaciona com a microbiota intestinal, é a função dos ácidos biliares. Estes são sintetizados a partir do colesterol com uma ampla gama de funções fisiológicas. Os ácidos biliares podem não apenas facilitar a digestão e a absorção de alimentos lipossolúveis, mas também preservar a barreira intestinal e prevenir a translocação bacteriana (Ma, Zhou \& Li, 2017).

Ácidos biliares costumam ter propriedades antimicrobianas fortes e a microbiota intestinal pode influenciar a homeostase do pool dos mesmos, por desconjugar e metabolizar os ácidos biliares primários em ácidos biliares secundários no trato intestinal, que estão envolvidos na modulação de lipídios e metabolismo energético durante a formação da DHGNA (Moraes, Silva, Almeida-Pititto \& Ferreira, 2014).

A microbiota intestinal tem a capacidade de promover o desenvolvimento da DHGNA. E nesse aspecto, a conversão da colina em dimetilamina tóxica e trimetilamina, mediada por esses microrganismos, apresentam-se como um dos principais meios. Os produtos dessa conversão são transportados para o fígado e convertidos em Óxido de Trimetilamina (TMAO), causando inflamação entre outros danos ao tecido hepático que contribuem para a evolução da doença (MA et al., 2017).

Vale destacar que a colina não é apenas um componente indispensável dos fosfolipídios da membrana celular, mas também desempenha um papel importante no metabolismo lipídico. Esse nutriente facilita o transporte lipídico nos hepatócitos e previne o acúmulo anormal de lipídios no fígado, enquanto que sua deficiência geralmente leva à esteatose hepática. A estreita relação entre a microbiota intestinal e o metabolismo da colina fornece uma justificativa importante para a terapia direcionada à microbiota intestinal para a DHGNA (Corbin \& Zeisel, 2012).

\section{Probióticos, Prebióticos e Simbióticos}

De acordo com a Organização Mundial da Saúde (OMS), probióticos são microrganismos vivos que administrados em quantidades adequadas modulam a microbiota intestinal estimulando a proliferação de bactérias boas em detrimento de bactérias potencialmente prejudiciais. Dessa forma, os probióticos conferem benefícios à saúde do hospedeiro por contribuírem para o alívio de sintomas gastrointestinais como dor, distensão abdominal e diarréia (Brasil, 2002).

Os critérios mínimos exigidos para um produto ser considerado probiótico incluem conter especificação por gênero e cepa, ser de origem humana, conter bactérias vivas, ser 
resistente aos processamentos tecnológicos de fabricação e ao ambiente ácido estomacal, à bile e às enzimas pancreáticas, ter capacidade de colonização e de adesão às células da mucosa intestinal, produzir substâncias antimicrobianas contra bactérias patogênicas, auxiliar na prevenção da translocação bacteriana, ser seguro ao uso humano e não apresentar patogenicidade (Guimarães, 2008).

Os principais microrganismos utilizados como suplementos probióticos são provenientes de mono ou multiculturas representadas principalmente por bactérias pertencentes aos gêneros Lactobacillus e Bifidobacterium e, em menor escala Enterococcus e Estreptococcus (Stefe, Ribeiro \& Ribeiro-Alves, 2008; Santos, 2010). No entanto, também podemos encontrar produtos em que os microrganismos utilizados são leveduras como Sacharomyces boulardii (Varavallo, Thomé \& Teshima, 2008).

Destaca-se que há outro modo de estimular o aumento do número de bactérias benéficas no cólon, por meio do uso de prebióticos. Estes são considerados importantes substratos que estimulam o crescimento dos microrganismos presentes no intestino. Os substratos não digeridos no intestino delgado, ao atingirem o intestino grosso são metabolizados por uma série de bactérias benéficas, gerando uma alteração positiva na microbiota, tornando-a saudável e proporcionando vários benefícios à saúde (Giovannini, 2007).

A constituição dos prebióticos se dá essencialmente por carboidratos, sendo monossacarídeos, dissacarídeos, oligossacarídeos e até polissacarídeos. São encontrados em alimentos como o tomate, a cebola, a aveia, o trigo e a banana, como também em tubérculos, como o bulbo e o yacon (Tamura et al., 2007). São classificados em solúveis, insolúveis ou mistos, podendo ser fermentáveis ou não. As fibras de maior importância utilizadas como prebióticos, são o Frutooligossacarídeos (FOS) e a inulina (Polakowski, 2015).

Já os simbióticos consistem na associação de probióticos e prebióticos, presentes em alimentos contendo simultaneamente os dois microrganismos, resultando em produtos com características funcionais de ambos os grupos, proporcionando benefícios a saúde do consumidor. Tal combinação pode proporcionar no aumento da eficácia dos microrganismos benéficos no trato intestinal (Pineiro \& Stanton, 2007).

Vários são os efeitos descritos pelo consumo de alimentos simbióticos, dentre os quais, destacam-se: a melhora da inflamação pela redução de citocinas pró-inflamatórias, a melhora do sistema imune, melhora da saúde intestinal, aumento da massa magra e redução da massa gorda, entre outros encontrados em estudos que evidenciaram a existência de tais benefícios (Souza, 2010). Nesse aspecto, pesquisadores têm buscado analisar os efeitos 
positivos de probióticos, prebióticos e simbióticos, no intuito de fortalecer a ideia do uso desses componentes como intervenção em complicações, tal qual a DHGNA.

\section{Resultados}

$\mathrm{Na}$ Tabela 1, a seguir, estão dispostos os resultados encontrados sobre o efeito de probióticos, prebióticos e simbióticos na DHGNA.

Tabela 1. Estudos que investigaram a ação de probióticos, prebióticos e simbióticos na DHGNA.

\begin{tabular}{|c|c|c|}
\hline $\begin{array}{c}\text { AUTORES/AN } \\
\text { O }\end{array}$ & DESCRIÇÃO DO ESTUDO & RESULTADOS \\
\hline \multicolumn{3}{|c|}{ Probióticos } \\
\hline $\begin{array}{l}\text { Cano, } \\
\text { Santacruz, } \\
\text { Trejo \& } \\
\text { Sanz, } 2013\end{array}$ & $\begin{array}{l}\text { Objetivou-se avaliar os efeitos } \\
\text { da administração de } \\
\text { Bifidobacterium } \\
\text { pseudocatenulatum } \\
\text { alterações metabólicas e } \\
\text { imunológicas } \\
\text { camundongos obesos com } \\
\text { DHGNA. Estes foram } \\
\text { alimentados com dieta padrão } \\
\text { ou dieta hiperlipídica, } \\
\text { suplementada ou não com } \\
\text { Bifidobacterium } \\
\text { pseudocatenulatum por } 7 \\
\text { semanas. As avaliações } \\
\text { incluíram parâmetros } \\
\text { bioquímicos e imunológicos, } \\
\text { histologia do fígado, tecido } \\
\text { adiposo branco } \\
\text { intestinal e características } \\
\text { relacionadas à microbiota. }\end{array}$ & $\begin{array}{l}\text { A suplementação de } \\
\text { Bifidobacterium } \\
\text { pseudocatenulatum reduziu } \\
\text { propriedades inflamatórias } \\
\text { do conteúdo do intestino em } \\
\text { camundongos com DHGNA. }\end{array}$ \\
\hline
\end{tabular}




\begin{tabular}{|c|c|c|}
\hline $\begin{array}{c}\text { Okubo et al., } \\
2013\end{array}$ & $\begin{array}{l}\text { Objetivou-se analisar } \mathrm{o} \\
\text { desenvolvimento da } \\
\text { DHGNA em ratos. Portanto, } \\
\text { dividiram-se três grupos de } \\
\text { ratos, levando em consideração } \\
\text { a dieta, classificadas em: } \\
\text { normal, dieta indutora para } \\
\text { DHGNA e dieta indutora para } \\
\text { a DHGNA mais a } \\
\text { administração oral diária de } \\
\text { Lactobacillus casei durante } \\
\text { seis semanas. }\end{array}$ & $\begin{array}{l}\text { A intervenção com Lactobacillus } \\
\text { casei suprimiu marcadamente o } \\
\text { desenvolvimento da DHGNA } \\
\text { induzida por dieta, com } \\
\text { concentrações séricas de } \\
\text { lipopolissacarídeos reduzidas, } \\
\text { supressão da inflamação e } \\
\text { fibrose no fígado e redução da } \\
\text { inflamação do cólon. }\end{array}$ \\
\hline Li et al., 2014 & $\begin{array}{l}\text { Buscou-se avaliar o efeito do } \\
\text { Lactobacillus plantarum na } \\
\text { função hepática, estresse } \\
\text { oxidativo e metabolismo } \\
\text { lipídico em ratos com DHGNA } \\
\text { induzida por dieta rica em } \\
\text { gordura. Para isso, os ratos } \\
\text { foram divididos em quatro } \\
\text { grupos: o grupo Dieta Normal } \\
\text { (DN); o grupo com Dieta } \\
\text { Hiperlipídica (DH); e DH mais } \\
\text { Lactobacillus plantarum. }\end{array}$ & $\begin{array}{l}\text { Verificou-se que o tratamento } \\
\text { de Lactobacillus plantarum } \\
\text { durante cinco semanas restaurou } \\
\text { a função hepática e diminuiu os } \\
\text { níveis de acumulação de gordura } \\
\text { no fígado em ratos com DHGNA. } \\
\text { Além disso, a bactéria reduziu } \\
\text { significativamente a endotoxina e } \\
\text { as citocinas pró- inflamatórias e } \\
\text { regulou a flora bacteriana no cólon } \\
\text { e a expressão do metabolismo } \\
\text { lipídico no fígado. }\end{array}$ \\
\hline $\begin{array}{l}\text { Ren, Huang \& } \\
\text { Cheng, } 2014\end{array}$ & $\begin{array}{l}\text { Objetivaram explorar } 0 \\
\text { possível mecanismo para os } \\
\text { efeitos protetores da dieta de } \\
\text { mirtilo e bifidobactérias na } \\
\text { DHGNA. Ratos com doença } \\
\text { hepática gordurosa não } \\
\text { alcoólica foram divididos em } \\
\text { dois grupos, sendo um grupo } \\
\text { alimentado com suco de mirtilo } \\
\text { e bifidobactérias e o outro } \\
\text { apenas com suco de mirtilo. }\end{array}$ & $\begin{array}{l}\text { O grupo alimentado com suco de } \\
\text { mirtilo e bifidobactérias } \\
\text { apresentou maiores índices das } \\
\text { enzimas superóxido dismutase, } \\
\text { glutationa peroxidase e de HDL, } \\
\text { em relação ao outro grupo. O } \\
\text { aumento significativo desses } \\
\text { índices possibilitou uma melhora } \\
\text { na DHGNA nos ratos analisados. }\end{array}$ \\
\hline $\begin{array}{l}\text { Sepideh et al., } \\
2016\end{array}$ & $\begin{array}{l}\text { O objetivo do estudo foi } \\
\text { investigar os efeitos da } \\
\text { suplementação de probióticos } \\
\text { sobre os índices glicêmicos e } \\
\text { inflamatórios em pacientes } \\
\text { com DHGNA. Ensaio clínico } \\
\text { randomizado realizado em } 42 \\
\text { pacientes com DHGNA. Os } \\
\text { participantes dos grupos } \\
\text { intervenção e controle } \\
\text { consumiram duas cápsulas / dia } \\
\text { do probiótico ou placebo, } \\
\text { respectivamente, por oito } \\
\text { semanas. Glicemia em jejum, }\end{array}$ & $\begin{array}{l}\text { Os resultados relacionados a } \\
\text { glicemia em jejum, insulina, } \\
\text { resistência à insulina e IL-6 } \\
\text { foram significativamente } \\
\text { diferentes entre os grupos após a } \\
\text { intervenção (p <0,05), enquanto } \\
\text { o TNF- } \alpha \text { não foi } \\
\text { significativamente modificado } \\
\text { (p>0,05). No grupo probiótico, a } \\
\text { insulina, a resistência à insulina, } \\
\text { o TNF- } \alpha \text { e a IL-6 diminuíram } \\
\text { significativamente no final do } \\
\text { estudo em comparação com o } \\
\text { início do estudo. }\end{array}$ \\
\hline
\end{tabular}




\begin{tabular}{|c|c|c|}
\hline & $\begin{array}{l}\text { insulina, resistência à insulina, } \\
\text { TNF- } \alpha \text { e IL-6 foram medidos } \\
\text { no início e no final do estudo. }\end{array}$ & \\
\hline Sohn, 2015 & $\begin{array}{l}\text { Objetivaram investigar os } \\
\text { efeitos protetores e possíveis } \\
\text { mecanismos de Lactobacillus } \\
\text { paracasei na DHGNA. } 30 \\
\text { camundongos machos foram } \\
\text { distribuidos em três grupos e } \\
\text { mantidos por dez semanas: } \\
\text { grupo controle (ração padrão), } \\
\text { grupo modelo NASH (dieta } \\
\text { rica em gordura + 10\% frutose) } \\
\text { e grupo L Lactobacillus } \\
\text { paracasei (modelo NASH } \\
\text { com L Lactobacillus paracasei } \\
\text { ). A histologia hepática, os } \\
\text { níveis séricos de } \\
\text { aminotransferase e os níveis de } \\
\text { expressão gênica hepática } \\
\text { foram medidos. }\end{array}$ & $\begin{array}{l}\text { Deposição de gordura hepática e } \\
\text { nível sérico de Alanina- } \\
\text { aminotransferase } \\
\text { significativamente menores no } \\
\text { grupo L. paracasei do que no } \\
\text { grupo NASH (p <0,05). O grupo } \\
L \text { Lactobacillus paracasei } \\
\text { apresentou menor TNF- } \alpha \text {, } \\
\text { Proteína Quimiotática de } \\
\text { Monócitos-1 } \\
\text { Interleucina } 4 \text { (IL-4), receptores } \\
\text { ativados por Proliferador de } \\
\text { Peroxissoma Gama (PPAR- } \gamma) \\
\text { e PPAR- } \delta \\
\text { comparação com o grupo NASH } \\
\text { (p<0,05). }\end{array}$ \\
\hline $\begin{array}{l}\text { Manzhalii, } \\
\text { virchenko, } \\
\text { falalyeyeva, } \\
\text { beregova \& } \\
\text { stremmel, } \\
2017\end{array}$ & $\begin{array}{l}\text { Objetivou-se avaliar o efeito } \\
\text { terapêutico de um coquetel } \\
\text { probiótico contendo } \\
\text { Lactobacilli, Bifidobacteria e } \\
\text { Streptococcus thermophilus na } \\
\text { esteato - hepatite não alcoólica. } \\
\text { No estudo, } 75 \text { pacientes com } \\
\text { esteato - hepatite não alcoólica, } \\
\text { alimentados com dieta } \\
\text { hipolipídica / hipocalórica, } \\
\text { foram aleatoriamente divididos } \\
\text { em grupo controle e grupo } \\
\text { experimental, sendo que este } \\
\text { último recebeu o coquetel } \\
\text { probiótico uma vez ao dia por } \\
12 \text { semanas. }\end{array}$ & $\begin{array}{l}\text { O IMC e o colesterol sérico } \\
\text { foram reduzidos pela dieta } \\
\text { hipolipídica/ hipocalórica, mas a } \\
\text { alanina aminotransferase não foi. } \\
\text { No entanto, o tratamento de curto } \\
\text { prazo (12 semanas) com o } \\
\text { coquetel probiótico causou uma } \\
\text { redução significativa (> 20\%) da } \\
\text { alanina aminotransferase sérica } \\
\text { em comparação com os } \\
\text { controles, indicando atenuação } \\
\text { da inflamação. Por conseguinte, } \\
\text { a rigidez do fígado foi diminuída } \\
\text { no grupo tratado com probiótico } \\
\text { em comparação com o grupo } \\
\text { controle (P <0,05). Além disso, } \\
\text { uma diminuição mais } \\
\text { significativa no IMC e no } \\
\text { colesterol sérico foi observada no } \\
\text { grupo tratado com probióticos } \\
\text { em comparação com o controle } \\
\text { (P <0,05). No entanto, a redução } \\
\text { da gama-glutamiltransferase } \\
\text { como marcador de esteatose foi } \\
\text { insignificante. A composição da } \\
\text { microbiota de fezes em pacientes } \\
\text { tratados com probióticos } \\
\text { demonstrou uma mudança em } \\
\text { direção a um padrão normal para }\end{array}$ \\
\hline
\end{tabular}




\begin{tabular}{|c|c|c|}
\hline & & $\begin{array}{l}\text { todas as espécies bacterianas } \\
\text { examinadas. Nenhum evento } \\
\text { adverso foi observado em } \\
\text { qualquer paciente durante o } \\
\text { estudo. }\end{array}$ \\
\hline $\begin{array}{l}\text { Kobyliak et } \\
\text { al., } 2018\end{array}$ & $\begin{array}{l}\text { No estudo, foi realizado um } \\
\text { ensaio clínico randomizado } \\
\text { duplo-cego, envolvendo a } \\
\text { utilização de probiótico e } \\
\text { placebo em pacientes com } \\
\text { diabetes tipo } 2 \text { portadores de } \\
\text { DHGNA. Um total de } 58 \\
\text { pacientes preencheram os } \\
\text { critérios para inclusão. Eles } \\
\text { foram aleatoriamente } \\
\text { designados para receber o } \\
\text { multi-probiótico "Symbiter" } \\
\text { (biomassa concentrada de } 14 \\
\text { gêneros de bactérias } \\
\text { probióticas Bifidobacterium, } \\
\text { Lactobacillus, Lactococcus, } \\
\text { Propionibacterium) ou placebo } \\
\text { por } 8 \text { semanas administrado } \\
\text { como uma formulação de sachê } \\
\text { em tratamento duplo-cego. }\end{array}$ & $\begin{array}{l}\text { No grupo probiótico, o índice de } \\
\text { fígado gorduroso diminuiu } \\
\text { significativamente (p <0,001), } \\
\text { mas não se alterou no grupo } \\
\text { placebo (p=0,367). Em ambos } \\
\text { os grupos, foi detectada uma } \\
\text { redução discreta, mas não } \\
\text { significativa de rigidez do fígado } \\
\text { medida por Elastografia por } \\
\text { Ondas de Cisalhamento. A } \\
\text { análise dos desfechos } \\
\text { secundários mostrou que os } \\
\text { probióticos reduziram o nível } \\
\text { sérico de aspartato transaminase } \\
\text { e gama-glutamiltransferase. } \\
\text { Entre os marcadores do estado } \\
\text { inflamatório sistêmico crônico, } \\
\text { apenas os níveis de TNF- } \alpha \text { e IL-6 } \\
\text { mudaram significativamente } \\
\text { após o tratamento com o } \\
\text { probiótico. }\end{array}$ \\
\hline
\end{tabular}

\section{PREBIÓTICOS}

Holscher et

al., 2012

Objetivaram avaliar a tolerância gastrointestinal e a microbiota fecal, o $\mathrm{pH}$ e as concentrações de AGCC de lactentes que consomem fórmulas comou sem prebióticos. Os Bebês alimentados com fórmula consumiram uma fórmula de soro parcialmente hidrolisada com ou sem $4 \mathrm{~g} / \mathrm{L}$ de galactooligossacarídeos e frutooligossacarídeos $\quad(9: 1)$.

Bactérias fecais, pH e AGCC foram avaliados no início do estudo. Os cuidadores dos pacientes registraram as características e comportamento das fezes por dois dias antes das visitas de três e seis semanas.

Pachikian et al., 2013
Objetivaram analisar os efeitos de fruto - oligossacarídeos
Fezes de crianças alimentadas com fórmulas contendo galactooligossacarídeos e frutooligossacarídeos tiveram um maior número absoluto $(\mathrm{P}=$ $0,0083)$ e proporção $(\mathrm{P}=0,0219)$ de bifidobactérias do que crianças alimentadas com fórmulas sem a presença de prebióticos e não diferiram das crianças que se alimentavam por meio da amamentação. 


\begin{tabular}{|c|c|c|}
\hline & $\begin{array}{l}\text { dietéticos fermentáveis na } \\
\text { DHGNA. Ratos com DHGNA } \\
\text { induzida por dieta pobre em } \\
\text { ácidos graxos ômega-3 foram } \\
\text { submetidos a tratamento com } \\
\text { fruto - oligossacarídeos } \\
\text { dietéticos fermentáveis por um } \\
\text { período de } 10 \text { dias. }\end{array}$ & $\begin{array}{l}\text { suplementação reduziu o } \\
\text { acúmulo de triglicerídeos } \\
\text { hepáticos através da estimulação } \\
\text { do receptor estimulante da } \\
\text { oxidação de ácidos graxos e } \\
\text { diminuiu o acúmulo de colesterol } \\
\text { pela inibição da síntese de } \\
\text { colesterol dependente de } \\
\text { proteína. Por meio de biópsia, os } \\
\text { autores confirmaram a inibição } \\
\text { da oxidação de ácidos graxos. Os } \\
\text { resultados culminaram em } \\
\text { melhora regressão do } \\
\text { desenvolvimento da DHGNA. }\end{array}$ \\
\hline $\begin{array}{l}\text { Lambert et al., } \\
2015\end{array}$ & 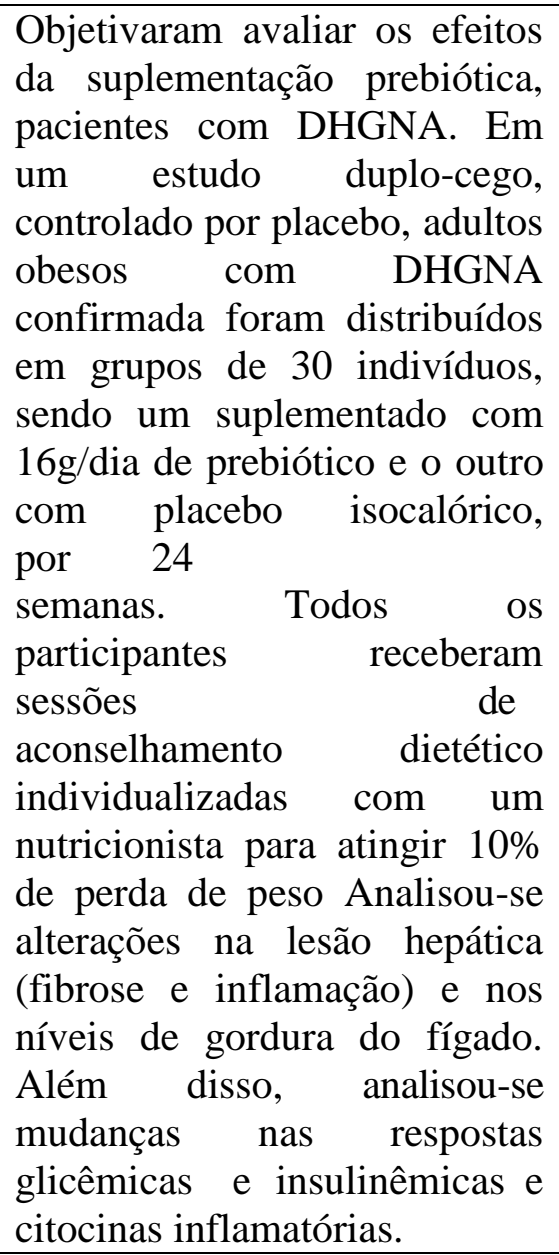 & $\begin{array}{l}\text { Observou-se melhora na lesão } \\
\text { hepática por meio da redução de } \\
\text { marcadores não invasivos } \\
\text { bioquímicos de fibrose } \\
\text { inflamação. }\end{array}$ \\
\hline $\begin{array}{l}\text { Singh et al., } \\
2016\end{array}$ & $\begin{array}{lrr}\text { Objetivou-se } & \text { avaliar } & \text { uma } \\
\text { combinação cobiótica } & \text { de } \\
\text { licopeno (antioxidante) } & \text { e } \\
\text { isomalto-oligossacarídeos } \\
\text { (IMOs, um prebiótico) para } \\
\text { prevenção de alterações } \\
\text { induzidas por dieta } \\
\text { hiperlipídica. Camundongos } \\
\text { albinos Swiss machos foram } \\
\text { alimentados com dieta de }\end{array}$ & $\begin{array}{l}\text { Foi observado melhora em } \\
\text { diversos fatores que contribuem } \\
\text { para o desenvolvimento da } \\
\text { doença hepática alcoólica não } \\
\text { gordurosa. }\end{array}$ \\
\hline
\end{tabular}




\begin{tabular}{|c|c|c|}
\hline & $\begin{array}{l}\text { pellets normal, ou dieta } \\
\text { hiperlipídica e licopeno (5 e } 10 \\
\mathrm{mg} / \mathrm{kg} \text {, com e sem acréscimo } \\
\text { de isomalto- oligossacarídeos } \\
(0,5 \text { e } 1 \mathrm{~g} / \mathrm{kg}) \text { por } 12 \text { semanas. } \\
\text { Adiposidade sistêmica, } \\
\text { tolerância à glicose, } \\
\text { sensibilidade à insulina, } \\
\text { reguladores alimentares no } \\
\text { hipotálamo, hepatosteatose e } \\
\text { inflamação hepática, ácidos } \\
\text { graxos de cadeia curta cecal, } \\
\text { citocinas inflamatórias séricas, } \\
\text { morfologia intestinal e } \\
\text { alterações em micróbios } \\
\text { intestinais selecionados foram } \\
\text { estudados. }\end{array}$ & \\
\hline $\begin{array}{l}\text { Matsumoto et } \\
\text { al.,2017 }\end{array}$ & 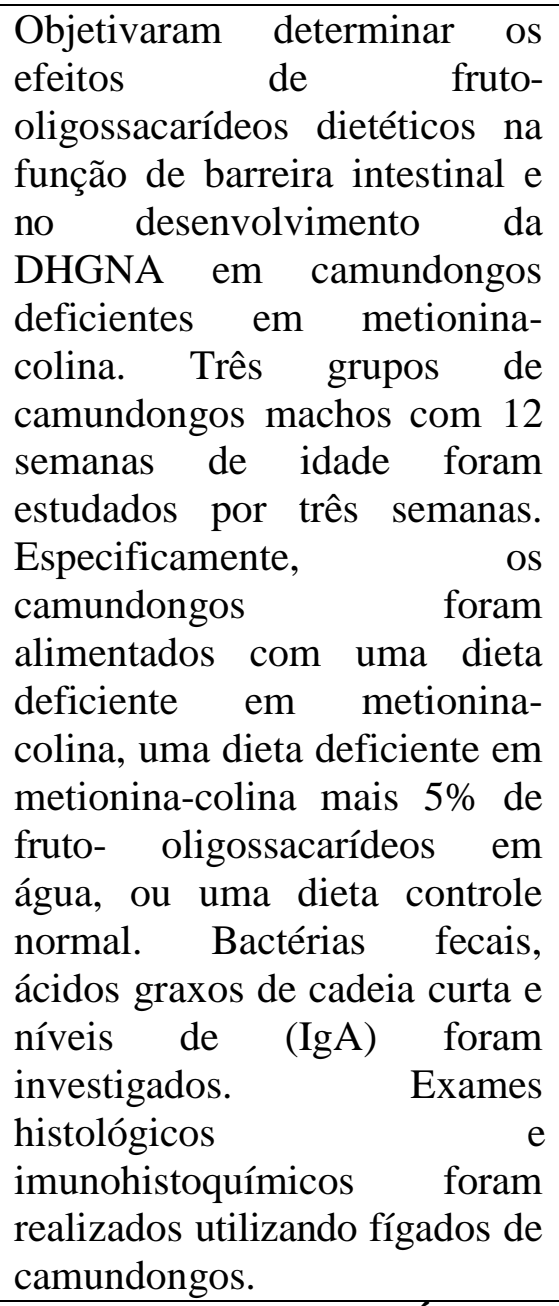 & $\begin{array}{l}\text { Camundongos deficientes em } \\
\text { metionina-colina que receberam } \\
5 \% \text { de frutoligossacarídeos } \\
\text { exibiram esteatose hepática } \\
\text { significativamente diminuída (p } \\
=0,003) \text { diminuição da } \\
\text { inflamação hepática }(\mathrm{p}=0,005) \text {, } \\
\text { diminuição da proporção de } \\
\text { células de Kupffer }(\mathrm{p}=0,01) \text {, } \\
\text { diminuição da expressão de } \\
\text { TLR4 }(\mathrm{p}=0,04) \text { e aumentos nas } \\
\text { concentrações fecais de ácidos } \\
\text { graxos de cadeia curta e IgA (p } \\
<0,04) \text { em comparação com os } \\
\text { achados em camundongos } \\
\text { deficientes em metionina-colina } \\
\text { que não receberam este } \\
\text { prebiótico. }\end{array}$ \\
\hline \multicolumn{3}{|c|}{ SIMBIÓTICOS } \\
\hline $\begin{array}{l}\text { Eslamparast } \\
\text { et al., } 2014\end{array}$ & $\begin{array}{l}\text { Objetivou-se avaliar os efeitos } \\
\text { da suplementação com o } \\
\text { simbiótico na fibrose hepática, } \\
\text { enzimas hepáticas e } \\
\text { marcadores inflamatórios em }\end{array}$ & 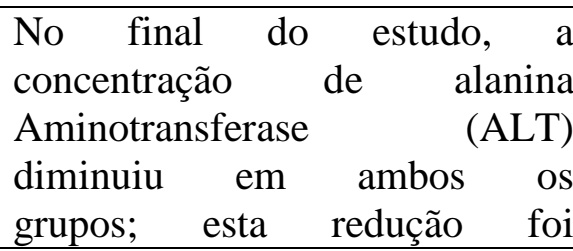 \\
\hline
\end{tabular}




\begin{tabular}{|c|c|c|}
\hline & $\begin{array}{l}\text { pacientes com DHGNA. } \\
\text { Ensaio clínico randomizado, } \\
\text { duplo-cego, controlado por } \\
\text { placebo conduzido como um } \\
\text { estudo piloto, onde } 52 \\
\text { pacientes com DHGNA foram } \\
\text { suplementados duas vezes ao } \\
\text { dia por } 28 \text { semanas com uma } \\
\text { cápsula simbiótica ou placebo. } \\
\text { Ambos os grupos foram } \\
\text { aconselhados a seguir uma } \\
\text { dieta equilibrada em energia e } \\
\text { recomendações de atividade } \\
\text { física. }\end{array}$ & $\begin{array}{l}\text { significativamente } \\
\text { grupo simbiótico. Além disso, } \\
\text { marcadores de estresse } \\
\text { oxidativo } \\
\text { concentrações menores nos } \\
\text { pacientes suplementados com } \\
\text { simbióticos. }\end{array}$ \\
\hline $\begin{array}{l}\text { Raso et al., } \\
2014\end{array}$ & $\begin{array}{l}\text { Buscou-se } \\
\text { uso de unalisar o efeito do } \\
\text { composto por Lactobacillus } \\
\text { paracasei } \\
\text { arabinogalactana e fruto- } \\
\text { oligossacarídeos em ratos com } \\
\text { DHGNA. Esteatose } \\
\text { inflamação hepática, tolerância } \\
\text { à glicose, sinalização de } \\
\text { insulina e permeabilidade } \\
\text { intestinal foram estudados. }\end{array}$ & $\begin{array}{l}\text { O simbiótico melhorou muitos } \\
\text { aspectos da resistência a insulina, } \\
\text { como resposta em jejum, } \\
\text { homeostase hormonal e controle } \\
\text { glicêmico. Preveniu } \\
\text { comprometimento da sinalização } \\
\text { hepática de insulina, reduzindo a } \\
\text { fosforilação do substrato um do } \\
\text { receptor de insulina em Ser } 307 \text { e } \\
\text { regulando negativamente a } \\
\text { produção de citocinas } \\
\text { inflamatórias. O simbiótico } \\
\text { também preservou a integridade } \\
\text { da barreira intestinal e reduziu a } \\
\text { quantidade relativa de } \\
\text { Enterobacteriales } \\
\text { negativas Gram- } \\
\text { e Escherichia coli na mucosa } \\
\text { colônica. }\end{array}$ \\
\hline $\begin{array}{l}\text { Asgaharian, } \\
2016\end{array}$ & $\begin{array}{l}\text { Objetivou determinar os efeitos } \\
\text { do simbiótico na PCR, enzimas } \\
\text { hepáticas e } \\
\text { ultrassonográficos } \\
\text { pacientes com } \\
\text { Ensaio clínico randomizado, } \\
\text { duplo-cego e controlado por } \\
\text { placebo realizado com oitenta } \\
\text { pacientes diagnosticados com } \\
\text { phGNA. Os } \\
\text { participantes receberam uma } \\
\text { puplementação simbiótica, } \\
\text { cor meio de uma cápsula } \\
\text { espécies } 500 \text { mg (contendo sete } \\
\text { probióticas de bactérias } \\
\text { frutooligossacarídeos) ou uma }\end{array}$ & $\begin{array}{l}\text { No grupo simbiótico, a } \\
\text { graduação do ultrassom diminuiu } \\
\text { significativamente em } \\
\text { comparação com o valor basal (P } \\
<0,005 \text { ), mas a suplementação } \\
\text { simbiótica não foi associada a } \\
\text { alterações nos níveis de ALT e } \\
\text { Aspartato Transaminase (AST). } \\
\text { No grupo placebo, não houve } \\
\text { mudança significativa no grau de } \\
\text { esteatose, enquanto os níveis de } \\
\text { ALT e AST foram } \\
\text { significativamente aumentados } \\
\text { (P = 0,002, P = 0,02, } \\
\text { respectivamente). Os valores de } \\
\text { PCR permaneceram estáticos } \\
\text { em qualquer grupo. }\end{array}$ \\
\hline
\end{tabular}




\begin{tabular}{|c|c|c|}
\hline & $\begin{array}{l}\text { cápsula de placebo por dia } \\
\text { durante } 8 \\
\text { graduação do ultrassomanas. A PCR } \\
\text { e as enzimas hepáticas foram } \\
\text { avaliadas na linha de base e no } \\
\text { final do estudo. }\end{array}$ & \\
\hline Ferolla et al., 2016 & 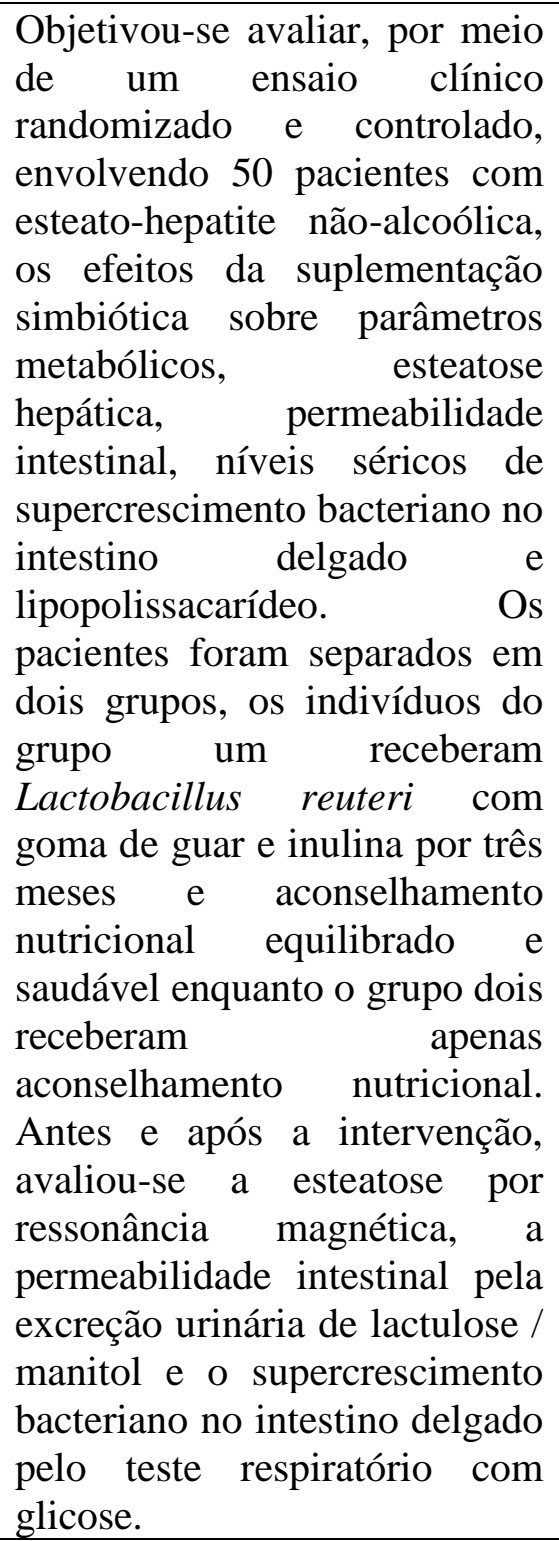 & $\begin{array}{l}\text { Depois da intervenção, apenas o } \\
\text { grupo com suplementação } \\
\text { simbiótica apresentou redução na } \\
\text { esteatose, perda de peso, } \\
\text { diminuição do IMC e medida da } \\
\text { circunferência da cintura. O } \\
\text { simbiótico não melhorou a } \\
\text { permeabilidade intestinal ou os } \\
\text { níveis de lipopolissacarídeos. }\end{array}$ \\
\hline $\begin{array}{l}\text { Ekhlasi et al., } \\
2017\end{array}$ & 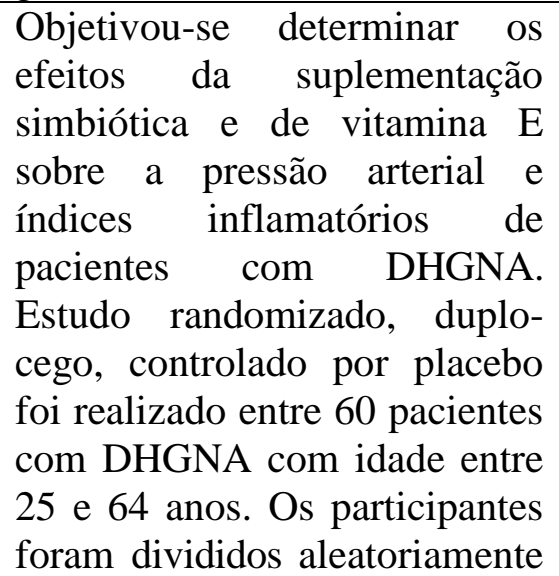 & $\begin{array}{l}\text { Alfa-tocoferol e suplementação } \\
\text { simbiótica entre pacientes com } \\
\text { DHGNA resultaram em } \\
\text { diminuição da PAS, níveis } \\
\text { séricos de MDA, TNF- } \alpha \text { e } \\
\text { enzimas hepáticas; no entanto, } \\
\text { eles não afetaram a PAD e a } \\
\text { concentração sérica de NO. }\end{array}$ \\
\hline
\end{tabular}




\begin{tabular}{|c|c|c|}
\hline & $\begin{array}{l}\text { em quatro grupos para receber } \\
400 \text { UI de alfa-tocoferol e } 2 \text { x } \\
10{ }^{8} \mathrm{UFC} / \mathrm{g} \text { suplemento } \\
\text { simbiótico por } 8 \text { semanas. Os } \\
\text { parâmetros antropométricos, } \\
\text { Pressão Arterial Sistólica } \\
\text { (PAS) e Pressão Arterial } \\
\text { Diastólica } \\
\text { Malondialdeído Sérico (MDA), } \\
\text { Óxido Nítrico (NO) e TNF- } \alpha \\
\text { foram avaliados no início e } \\
\text { após oito semanas de } \\
\text { intervenção. }\end{array}$ & \\
\hline $\begin{array}{l}\text { Mofidi et al., } \\
2017\end{array}$ & $\begin{array}{l}\text { Objetivaram avaliar a eficácia } \\
\text { da suplementação de } \\
\text { simbióticos em pacientes com } \\
\text { DHGNA com IMC normal ou } \\
\text { baixo. Realizou-se um ensaio } \\
\text { clínico randomizado, duplo- } \\
\text { cego, no qual cinquenta } \\
\text { pacientes com DHGNA } \\
\text { foram designados para tomar } \\
\text { um suplemento simbiótico ou } \\
\text { uma cápsula de placebo por } 28 \\
\text { semanas. Após o período, fez-se } \\
\text { uma análise de alguns } \\
\text { parâmetros bioquímicos, no } \\
\text { intuito de avaliar os efeitos da } \\
\text { suplementação. }\end{array}$ & $\begin{array}{l}\text { No final do estudo, esteatose } \\
\text { hepática e fibrose reduziram em } \\
\text { ambos os grupos; no entanto, a } \\
\text { redução média foi } \\
\text { significativamente maior no } \\
\text { grupo simbiótico do que no } \\
\text { grupo placebo (p<0,001). Além } \\
\text { disso, os níveis séricos de } \\
\text { açúcar no sangue em jejum, } \\
\text { TAG e a maioria dos mediadores } \\
\text { inflamatórios reduziram } \\
\text { significativamente no grupo } \\
\text { suplementado com simbiótico } \\
\text { em comparação com o grupo } \\
\text { placebo }(\mathrm{P}<0,05) \text {. }\end{array}$ \\
\hline
\end{tabular}

Fonte: Autores.

\section{Discussão}

A DHGNA é a doença hepática crônica mais comum devido à prevalência de obesidade em todo o mundo. Contudo, outros fatores contribuem para este índice, a exemplo das alterações da microbiota intestinal, que por meio de processos mediadores da inflamação, resistência à insulina, alterações nos ácidos biliares e metabolismo da colina, contribuem para o desenvolvimento da DHGNA. Nesse aspecto, ressalta-se a importância das terapias direcionadas à microbiota intestinal frente a DHGNA, através do uso de probióticos, prebióticos, simbióticos, antibióticos e alguns componentes ativos de ervas medicinais (Mouzaki \& Bandsma, 2015).

Na Tabela 1 encontram-se artigos que enfatizam o efeito do uso de probióticos, prebióticos e simbióticos no desenvolvimento da DHGNA. Observa-se melhora em alguns 
parâmetros que contribuem para a regressão da doença, como: ação de enzimas antioxidantes, redução da adiposidade, inflamação e fibrose no fígado, regulação da flora bacteriana intestinal, entre outros.

Tratando-se das bactérias probióticas, estudos relatam que as mesmas previnem o dano hepático e mantêm a função de barreira colônica em animais. E nesse cenário, encontram-se as bactérias lácticas, também reconhecidas como uma variedade probiótica representativa, comercialmente disponível como alimento saudável em vários países e prescrita como medicamento para distúrbios intestinais, como a diarreia (Okubo et al., 2013).

Estudos de Li et al. (2014), Okubo et al. (2013) e Sohn et al. (2015), presentes na Tabela 1, destacaram a contribuição de bactérias do gênero Lactobacillus na regressão da DHGNA, por meio da redução de inúmeros fatores que contribuem para o desenvolvimento dessa doença. De forma semelhante, no trabalho de Kim et al. (2016), foi observado por meio da suplementação de Lactobacillus rhamnosus em ratos com DHGNA, aumento da abundância de bactérias benéficas, melhorando a função da barreira intestinal e atenuando a inflamação hepática, bem como o efeito redutor de colesterol através da inibição da via de sinalização FXR e FGF15 (fator de crescimento de fibroblastos).

Bactérias do gênero Bifidobactérias são agentes com ação probiótica no trato gastrointestinal em mamíferos e que desempenham efeitos benéficos ao organismo. Nesse contexto, Cano et al. (2013) e Ren et al. (2014), avaliando a ingestão dessas bactérias por ratos com DHGNA, observaram melhora da resposta imune e flora intestinal, com uma consequente regressão da doença presente, como mostra a Tabela 1.

Resultados semelhantes puderam ser observados no estudo de Chen et al. (2012), onde ratos alimentados com dietas hiperlipídicas e suplementados com Bifidobacterium bifidum melhoraram significativamente o acúmulo de gordura visceral e a sensibilidade à insulina. Os mesmos resultados foram observados no estudo de Ma et al. (2017).

Os prebióticos podem ser definidos como um ingrediente fermentado que permite alterações na composição e/ou atividade na microflora gastrointestinal, conferindo benefícios ao bem-estar e à saúde do hospedeiro. Constantemente, estudos têm mostrado a eficiência dos prebióticos na prevenção ao desenvolvimento da DHGNA (Lambert et al., 2015; Matsumoto et al., 2017; Singh et al., 2016).

Em 2009, Cani et al. descobriram que os prebióticos da oligofrutose (uma mistura de fibras dietéticas fermentáveis) diminuíram os níveis plasmáticos de lipopolissacarídeos e citocinas, como também a expressão hepática de marcadores do estresse oxidativo em 
camundongos obesos. Uma melhoria na permeabilidade intestinal e produção de peptídeo semelhante ao Glucagon-2 (GLP-2) também foi mostrada.

Tagliari et al., 2017, avaliando a suplementação com o prebiótico frutooligossacarídeo em ratos com DHGNA induzida por dieta, observou atenuação da extensão da doença, restaurando a homeostase da microbiota intestinal e a função da barreira epitelial intestinal.

Simbióticos são compostos por microrganismos vivos que, quando administrados em doses adequadas, podem trazer benefícios à saúde do hospedeiro. São formados pela associação de um ou mais probióticos com um ou mais prebióticos (Flesch, Poziomyck \& Damin 2014). A relação entre simbióticos e DHGNA vem sendo destacado em muitos estudos, devido aos possíveis efeitos positivos atrelados a esses microrganismos (Asgaharian et al., 2016; Ekhlasi et al., 2017; Modifi et al., 2017).

Pesquisadores presentes na Tabela 1, ao verificarem os efeitos de formulações simbióticas, puderam destacar os benefícios atrelados a esses compostos, uma vez que os mesmos promoveram redução dos níveis de agentes inflamatórios, diminuição da esteatose hepática e melhora da flora intestinal.

Outros estudos também encontraram resultados semelhantes, como o de Eslamparast et al. (2014) que verificou o efeito terapêutico de um simbiótico contendo sete probióticos e oligofrutose ingeridos por pacientes com DHGNA em um ensaio clínico randomizado duplocego. Os resultados mostraram que a terapia simbiótica diminuiu significativamente os níveis de alanina aminotransferase, um marcador de lesão no fígado. Malaguarnera et al. (2012) observaram que a combinação de uma formulação simbiótica (B. longum e Frutoologossacarídeo) e estilo de vida em pacientes com DHGNA resultou em uma melhora muito maior em comparação à intervenção apenas no estilo de vida, incluindo redução dos níveis séricos de TNFa e PCR (proteína C-reativa).

Os estudos levantados no presente trabalho destacam que a terapia com probióticos, prebióticos e simbióticos podem ser considerados intervenções promissoras, visando a prevenção ou o tratamento da DHGNA. No entanto, mais validações clínicas são necessárias.

\section{Considerações Finais}

Diante do exposto, esta revisão consiste em um conjunto de estudos publicados nessa temática, a qual poderá nortear o desenvolvimento de pesquisas que possam elucidar mais relações entre, probióticos, prebióticos e simbióticos em relação a DHGNA. 
Estudos atuais mostram a microbiota intestinal como um importante fator contribuinte ao desenvolvimento da DHGNA. Nesse aspecto, terapias direcionadas à microbiota intestinal têm se tornado importantes ferramentas para o tratamento dessa doença, uma vez que existem na literatura, relatos experimentais que destacam uma série de benefícios por meio do uso de probióticos, prebióticos e simbióticos.

No entanto, os resultados presentes ainda mostram-se inconsistentes e algumas vezes contraditórios, o que pode ser justificado pelas diferenças na atividade bacteriana dos probióticos ou a disbiose diversificada entre os pacientes com DHGNA. Com isso, torna-se necessário mais estudos acerca do presente tema.

\section{Referências}

Asgharian, A. (2016). The Effect of Symbiotic Supplementation on Liver Enzymes, Creactive Protein and Ultrasound Findings in Patients with Non-alcoholic Fatty Liver Disease: A Clinical Trial. International Journal of Preventive Medicine, 7(59).

Bäckhed, F., Fraser, C. M., Ringel, Y., Sanders, M. E., Sartor, R. B., Sherman, P. M., Versalovic, J., Young, V., \& Finlay, B. B. (2012). Defining a healthy human gut microbiome: current concepts, future directions, and clinical applications. Cell Host \& Microbe, 12(5), 611-622.

BRASIL. (2002). Resolução RDC n 2, de 7 de janeiro de 2002. Aprova o Regulamento Técnico de Substâncias Bioativas e Probióticos Isolados com Alegação de Propriedades Funcionais e ou de Saúde. Diário Oficial da República Federativa do Brasil. Brasília, 9 jan. 2002. Recuperado em 27 junho, 2018, de <https://www.saude.rj.gov.br/comum/code/MostrarArquivo.php?C=MjI1Mw\%2C\%2C.>

Camargo, K. F. (2014). Estudo da inflamação e da autoimunidade na Doença Hepática gordurosa Não Alcoólica. Dissertação de Mestrado, Faculdade de Medicina, Universidade Estadual Paulista "Julio de Mesquita Filho", Botucatu, SP, Brasil.

Cani, P. D., Possemiers, S., Wiele, T. V., Guiot, Y., Everard, A., Rottier, O., Geurts, L., Naslain, D., Neyrinck, A., Lambert, D. M., Muccioli, G. G., \& Delzenne, N. M. (2009). 
Changes in gut microbiota control inflammation in obese mice through a mechanism involving GLP-2-driven improvement of gut permeability. Gut. 58, 1091-1103.

Cano, P. G., Santacruz, A., Trejo, F. M., \& Sanz, Y. (2013). Bifidobacterium CECT 7765 improves metabolic and immunological alterations associated with obesity in high-fat diet-fed mice. Obesity, 21, 2310-2321.

Chen, J., Wang, R., LI, X., \& Wang, R. (2012). Bifidobacterium adolescentis supplementation ameliorates visceral fat accumulation and insulin sensitivity in an experimental model of the metabolic syndrome. British Journal of Nutrition, 107, 1429-1434.

Corbin, K. D. \& Zeisel, S. H. (2012). Choline Metabolism Provides Novel Insights into Non-alcoholic Fatty Liver Disease and its Progression. Current Opinion in Gastroenterology, 28, 159-165.

Cotrim, H. P. (2009). Doença hepática gordurosa não alcoólica: história natural. Gazeta Médica da Bahia, 79, 46-47.

Ekhlasi, G., Zarrati, M., Agah, S., Hosseini, A. F., Hosseini, S. Shidfar, S., Soltani Aarbshahi, S. S., Razmpoosh, E., \& Shidfar, F. (2017). Effects of symbiotic and vitamin E supplemantation on blood pressure, nitric oxide and inflammatory factors in non-alcoholic fatty liver disease. EXCLI Journal, 16, 278-290.

Eslamparast, T., Poustchi, H., Zamani, F., Sharafkah, M., Malekzadeh, R., \& Hekmatdoost, A. (2014). Synbiotic supplementation in nonalcoholic fatty liver disease: A randomized, double-blind, placebo-controlled pilot study. The American. Journal of Clinical Nutrition, 99, $535-542$.

Ferolla, S. M., Couto, C. A., Costa Silva, L., Armiliato, G. N., Pereira, C. A., Martins, F. S., Ferrari, M. D. E. L., Vilela, E. G., Torres, H. O., Cunha, A. S., \& Ferrari, T. C. (2016). Beneficial Effect of Synbiotic Supplementation on Hepatic Steatosis and Anthropometric Parameters, But Not on Gut Permeability in a Population with Nonalcoholic Steatohepatitis. Nutrients, 8, 7. 
Flesh, A. G. T., Poziomyck, A. K., \& Damin, D. C. (2014). O uso terapêutico dos simbióticos. Arquivos Brasileiros de Ciurgia Digestiva, 27 (3), 206-209.

Giovannini, M., Agostoni, C., Riva, E., Salvini, F., Ruscitto, A., Zuccotti, G. V. \& Radaelli, G. (2007). A randomized prospective double blind controlled trial on effects of long term consumption of fermented milk containing Lactobacillus casei in preschool children with allergic asthma and/or rhinitis. Pediatric Research, 62, 215- 220.

Harryson, S. A. \& Day, C. P. Benefits of lifestyle modification in NAFLD. Gut, 56 (12), 1760-1769.

Holscher, H. D., Faust, K. L, Czerkies, L. A., Litov, R., Zieglerm, E. E., Lessin, H., Hatch, T., Sun. S., \& Tappenden, K. A. (2012). Effects of prebiotic-containing infant formula on gastrointestinal tolerance and fecal microbiota in a randomized controlled trial. Journal Parenteral and Enteral Nutrition, 36, 95-105.

Kim, Y., Edwards, N., \& Fenselau, C. (2016). Extracellular vesicle proteomes reflect developmental phases of Bacillus subtilis, Clinical Proteomics, 13 (6).

Kobyliak, N., Abenavoli, L., Mykhalchyshyn, G., Kononenko, L., Boccuto, L., KYRIIENKO, D., \& Dynnyk, O. (2018). A Multi-strain Probiotic Reduces the Fatty Liver Index, Cytokines and Aminotransferase levels in NAFLD Patients: Evidence from a Randomized Clinical Trial. Journal of Gastrointestinal and Liver Diseases, 27 (1), 41-49.

Lambert, J. E., Parnell, J. A., Eksteen, B., Raman, M., Bomhof, M. R., Rioux, K. P., Madsen, K. L., \& Reimer, R. A. (2015). Gut microbiota manipulation with prebiotics in patients with non-alcoholic fatty liver disease: A randomized controlled trial protocol. BMC Gastroenterology, 15 (169).

LI, C., Nie, S. P., Zhu, K. X., Ding, Q., LI, C., Xiong, T. \& Xie, M. Y. (2014). Lactobacillus plantarum NCU116 improves liver function, oxidative stress and lipid metabolism in rats with high fat diet induced non-alcoholic fatty liver disease. Journal of Functional Foods, 5, 3216-3223. 
Lirussi, F., Mastropasqua, E., Orando, S., \& Orlando, R. (2008). Probiotics for non-alcoholic fatty liver disease and/or steatohepatitis. Cochrane Database of Systematic Reviews. 2.

Ma, J., Zhou, Q., \& LI, H. (2017) Gut Microbiota and Nonalcoholic Fatty Liver Disease: Insights on Mecanisms and Therapy. Nutrientes, 9 (10).

Malaguarnera, M., Vacante, M., Antic, T., Giordano, M., Chisari, G., Acquaviva, R., Mastrojeni, S., Malaguarnera, G., Mistretta, A., LI Volti, G., \& Galvano, F. (2012). Bifidobacterium longum with fructo-oligosaccharides in patients with non alcoholic steatohepatitis. Digestive Diseases and Sciences, 57, 545-553.

Manzhalii, E., Virchenko, O., Falalyeyeva, T., Beregova, T., \& Stremmel, W. (2017).

Treatment efficacy of a probiotic preparation for non-alcoholic steatohepatitis: A pilot trial. Journal of Digestive Diseases, 18 (12), 698-703.

Matsumoto, K., Ichimura, M., Tsuneyama, K., Moritoki, Y., Tsunashima, H., Omagari, K., Hara, M., Yasuda, I., Miyakawa, H., \& Kikuchi, K. (2017). Fructo-oligosaccharides and intestinal barrier function in a methionine-choline-deficient mouse model of nonalcoholic steatohepatitis. PLoS ONE, 12.

Minemura, M., \& Shimizu, Y. (2015). Gut microbiota and liver diseases. World Journal of Gastroenterology, 21, 1691-1702.

Mofidi, F. (2017). Synbiotic supplementation in lean patients with non-alcoholic fatty liver disease: A pilot, randomised, double-blind, placebo-controlled, clinical trial. British Journal of Nutrition, 117, 662-668.

Mouzaki, M., \& Bandsma, R. (2015). Targeting the Gut Microbiota for the Treatment of NonAlcoholic Fatty Liver Disease. Current Drug Targets, 16, 1324-1331.

Moraes, A. C., F., Silva, I. T., Almeida-Pititto, B., \& Ferreira, S. R. G. (2014). Microbiota intestinal e risco cardiometabólico: mecanismos e modulação dietética. Arquivos Brasileiros de Endocrinologia Metabólica, 58 (4). 
Moschen, A. R., Kaser, S., \& Tilg, H. (2013). Non-alcoholic steatohepatitis: a microbiotadriven disease. Trends in Endocrinology \& Metabolism, 24(11), 537-545.

Odamaki, T., Xiao, J. Z., Iwabuchi, N., Sakamoto, M., Takahashi, M., Kondo, S., Iwatsuki, K., Kokubo, S., Togashi, H., Enomoto, T., \& Benno, Y. (2009). Fluctuation of fecal microbiota in individuals with Japanese cedar pollinosis during the pollen season and influence of probiotic intake. Journal of Investigational Allergology and Clinical Immunology, 17, 92-100.

Okubo, H., Sakoda, H., Kushiyama, A., Fujishiro, M., Nakatsu, Y., Fukushima, T., Matsunaga, Y., Kamata, H., Asahara, T., Yoshida, Y., Chonan, O., Iwashita, M., Nishimura, F., \& Asano, T. (2013). Lactobacillus casei strain Shirota protects against nonalcoholic steatohepatitis development in a rodent model. American Journal of PhysiologyGastrointestinal and Liver Physiology, 305, 911-918.

Oliveira, A., \& Aarestrup, F. M. (2012). Avaliação nutricional e atividade inflamatória sistêmica de pacientes com câncer colorretal submetidos à suplementação com simbiótico. Arquivos Brasileiros de Cirurgia Digestiva, 25 (3), 147-153.

Pacífico, L., Nobili, V., Anania, C., Verdecchia, P., \& Chiesa, C. (2011). Pediatric nonalcoholic fatty liver disease, metabolic syndrome and cardiovascular risk. World Journal of Gastroenterology, 17, 3082-3091.

Pachikian, B. D., Essaghir, A., Demoulin, J. B., Catry, E., Neyrinck, A. M., Dewulf, E. M., Sohet, F. M., Portois, L., Clerbaux, L. A., Carpentier, Y. A., Possemiers, S., Bommer, G. T., Cani, P. D., \& Delzenne, N. M. (2013). Prebiotic approach alleviates hepatic steatosis: Implication of fatty acid oxidative and cholesterol synthesis pathways. Molecular Nutrition \& Food Research, 57, 347-359.

Pineiro, M., \& Stanton, C. (2007). Probiotic bacteria: legislative framework - requirements to evidence basis. Journal of Nutrition, 137, 850-853. 
Polakowski, C. B. (2015). Impacto do uso de simbióticos no pré-operatório de cirurgia por câncer colorretal. 2015. Dissertação DE Mestrado, Universidade Federal do Paraná, Curitiba, Brasil.

Portela, C. L. M., Melo, M. L. P., \& Sampaio, H. A. C. (2013). Aspectos fisiopatológicos e nutricionais da doença hepática gordurosa não-alcóolica (DHGNA). Revista Brasileira de Nutrição Clínica, 28 (1), 54-60.

Raso, G. M., Simeoli, R., Iacono, A., Santoro, A., Amero, P., Paciello, O., Russo, R., D'agostino, G., DI Costanzo, M., Canani, R. B., Calignano, A., \& Meli, R. (2014). Effects of a Lactobacillus paracasei B21060 based synbiotic on steatosis, insulin signaling and toll-like receptor expression in rats fed a high-fat diet. The Journal of Nutritional Biochemistry, 25, 81-90.

Ren, T., Huang, C., \& Cheng, M. Dietary blueberry and bifidobacteria attenuate nonalcoholic fatty liver disease in rats by affecting SIRT1-mediated signaling pathway. Oxidative Medicine and Cellular Longevity.

Salgado Júnior, W., Santos, J. S., Sankarakutty, A. K., \& Silva, E. C. (2006). Nonalcoholic fatty liver disease and obesity. Acta Cirúrgica Brasileira, 21, 72-78.

Santos, A. C. A. L. (2010). Uso de probióticos na recuperação intestinal. Curso de especialização em terapia nutricional. Rio de janeiro, Brasil. Recuperado em 17 janeiro, 2019, de http://doczz.com.br/doc/205720/uso-de-probi\%C3\%B3ticos-narecupera\%C3\%A7\%C3\%A3o-da-flora-intestinal.

Shen, J., Obin, M. S., \& Zhao, L. (2013). The gut microbiota, obesity and insulin resistance. Molecular Aspects of Medicine, 34, 39-58.

Singh, D. P., Khare, P., Zhu, J., Kondepudi, K. K., Singh, J., Baboota, R. K., Boparai, R. K., Khardori, R., Chopra, K., \& Bishnoi, M. (2016). A novel cobiotic-based preventive approach against high-fat diet- induced adiposity, nonalcoholic fatty liver and gut derangement in mice. International Journal of Obesity, 40, 487-496. 
Sohn, W. (2015). Lactobacillus paracaseiInduces M2-Dominant Kupffer Cell Polarization in a Mouse Model of Nonalcoholic Steatohepatitis. Digestive Diseases and Sciences, 60, 33403350 .

Souza, F. S. (2010) Prebióticos, probióticos e simbióticos na prevenção e tratamento das doenças alérgicas. Revista Paulista de Pediatria, 28 (1).

Sepideh, A.M., Karim, P., Hossein, A., Leila, R., Hamdollah, M., Mohammad, E. G., Mojtaba, S., Mohammad, S., Ghader, G., \& Seyed Moayed, A. (2016). Effects of Multistrain Probiotic Supplementation on Glycemic and Inflammatory Indices in Patients with Nonalcoholic Fatty Liver Disease: A Double-Blind Randomized Clinical Trial. Journal of the American College of Nutrition, 35 (6), 500-505.

Stefe, C. A., Ribeiro, R. L., \& Ribeiro-Alves, M. A. (2008). Probióticos, prebióticos e simbióticos- artigo de revisão. Saúde e Ambiente em Revista, 3 (1), 16-33.

Tagliari, E. et al. Impacto do uso de simbiótico na doença hepática gordurosa não alcoólica em modelo de ratos. Arquivos Brasileiros de Cirurgia Digestiva, v.30, n.3, p:211-215, 2017.

Tamura, M., Shikina, T., Morihana, T., Hayama, M., Kajimoto, O., Sakamoto, A., Kajimoto, Y., Watanabe, O., Nonaka, C., Shida, K., \& Nanno, M. (2007). Effects of probiotics on allergic rhinitis induced by Japanese cedar pollen: randomized double-blind, placebocontrolled clinical trial. Internatinal Archives of Allergy and Immunology, 143, 75-82.

Theophilo, I. P. P., \& Guimarães, N. G. (2008). Tratamento com probióticos na síndrome do intestino irritável. Comumicação em Ciências da Saúde, 19 (3), 271-281.

Varavalho, M. A., Thomé, J. N., \& Teshima, E. (2008). Aplicação de bactérias probióticas para profilaxia e tratamento de doenças gastrointestinais. Semina: Ciências Biológicas e da Saúde, 29 (1), 83-104.

Wree, A., Broderick, L., Canbay, A., Hoffman, H. M., \& Feldstein, A. E. (2013). From Nafld to NASH to cirrhosis-new insights into disease mechanisms. Nature Reviews Gastroenterology \& Hepatology, 10, 627-636. 
Research, Society and Development, v. 9, n. 8, e263982594, 2020

(CC BY 4.0) | ISSN 2525-3409 | DOI: http://dx.doi.org/10.33448/rsd-v9i8.2594

Porcentagem de contribuição de cada autor no manuscrito

Mickael de Paiva Sousa -26,6\%

Joyce Sousa Aquino Brito - 26,6\%

Pedro Lucas Alves Ferreira - 10,1\%

Suhelen Maria Brasil da Cunha Gama - 10,1\%

Betânia de Jesus e Silva de Almendra Freitas - 26,6\% 